\title{
New Method for the Selection of Multicopy Transformants of Pichia pastoris, Using 3-Amino-1,2,4 Triazol
}

BioTechniques 29:1094-1099 (November 2000)

\author{
Javier Menéndez, Bianca \\ García and Yurima Hidalgo \\ Centro de Ingeniería Genética y \\ Biotecnología, La Habana, Cuba
}

\section{INTRODUCTION}

The yeast Pichia pastoris has become an important host system for the production of recombinant heterologous proteins (4). Some of these proteins have been expressed at high levels, but in a number of cases, low-yield single-copy integrants have been generated (11). To overcome this problem, the integration of multiple copies of the expression cassette has usually been used, resulting in an increased yield of the expressed protein (16).

The proposed mechanisms by which multicopy transformants arise involve (i) single homologous recombination events that yield tandem integrated copies of the vector and (ii) vector integration mediated by an initial transplacement, followed by repeated integration of circles formed by in vivo ligation (2). Because of the low and unpredictable frequency of both of these events, a system for the screening of multicopy transformants has recently become available (Invitrogen, Carlsbad, CA, USA). This method permits a selection of yeast cells with multicopy inserts based on G418 resistance con-

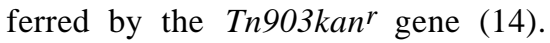
However, direct selection on G418 im mediately following transformation does not work with this approach, and the density of cells plated later on G418 plates is critical because of a large number of false positives obtained at high cell density. Although a second method using microplates to reduce the number of false positives has been recommended by the manufacturer, it is time consuming and laborious. Other related limitations of this method are the high cost of the G418 and the use of an antibiotic resistance gene to select the multicopy transformant yeast cells.

A very simple method that greatly improves this screening procedure was recently published by Fairlie et al. (5). It is based on growing the transformants on top of a nylon membrane, but has the same limitations mentioned above because of the use of G418.

Our group has developed a host-vector system in $P$. pastoris using a mutant strain (MP36) defective in the gene encoding imidazol glycerol P-dehydratase (HIS3). This mutant has been transformed successfully with the HIS3 gene from Saccharomyces cerevisiae (17). We have found a direct relationship between the integrated copy number of the expression vector that contains the HIS3 gene and the level of resistance to increased concentrations of 3-amino-1,2,4 triazol (3 AT), an inhibitor of the HIS3 gene product. Hence, we now propose a single selection method for the isolation of multicopy transformants in his $3^{-}$ strain of P. pastoris.

\section{MATERIALS AND METHODS}

\section{Strains and Culture Conditions}

P. pastoris strains BKMY-90 (CIGB, Havana, Cuba), MP36 his3- 
(17), MPDEX (10) and MPC3 (this study) were used throughout this study. These were grown at $28^{\circ} \mathrm{C}$ in a yeast peptone dextrose (YPD) medium [1\% $(\mathrm{w} / \mathrm{v})$ yeast extract, $2 \%(\mathrm{w} / \mathrm{v})$ peptone and $2 \%(\mathrm{w} / \mathrm{v})$ dextrose]. For selection during transformation experiments, a defined minimal yeast nitrogen base dextrose (YNBD) medium [0.67\% (v/v) yeast nitrogen base plus $2 \%(\mathrm{w} / \mathrm{v})$ dextrose] was used.

\section{Transformation of $\boldsymbol{P}$. pastoris}

Transformation of the MP36 strain of $P$. pastoris was carried out using the plasmid pPDEX (10) that contained the dextranase-encoding gene from Penicillium minioluteum previously digested with $P v u I I$. Spheroplast transformation was carried out with $10 \mu \mathrm{g}$ plasmid according to Cregg et al. (3). Up to $1 \mu \mathrm{g}$ plasmid was used for electroporation, and it was carried out essentially by the method of Becker and Guarente (1), with cells pulsed in 0.2$\mathrm{cm}$ electroporation cuvettes at $1500 \mathrm{~V}$, $25 \mu \mathrm{F}, 200 \Omega$, using a Gene Pulser with Pulse Controller (Bio-Rad Laboratories, Hercules, CA, USA). One milliliter of cold $1 \mathrm{M}$ sorbitol was added to the cuvettes immediately after pulsing, and $\mathrm{His}^{+}$transformants were recovered on minimal-agar plates (6) with $2 \%$ (w/v) dextrose.

\section{Determination of the Minimum Inhibitory Concentration of 3 AT}

A $P$. pastoris strain carrying several copies of the dextranase expression cassette was selected after Southern blot analysis and denominated MPC3. This strain and the MPDEX strain (which has only one copy inserted in its genome) were compared in their resistance to increased concentrations of 3 AT. For this experiment, both strains were grown in $100 \mathrm{~mL}$ minimal medium until they reached an $\mathrm{OD}_{530}$ of 0.5 . At this time the cells were pelleted by centrifugation and washed twice with sterile distilled water, and resuspended in $10 \mathrm{~mL}$ sterile water, and $10^{3}$ cells were plated on minimal medium plates containing different concentrations of 3 AT (0.5-120 mM). After three days, the lowest concentration inhibiting growth was determined for each strain.

\section{Secondary Selection for Multicopy Transformants Using 3 AT}

Transformants obtained either by electroporation or spheroplasting were selected on minimal medium plates lacking histidine. After this initial selection, transformants were isolated from the plates and resuspended independently in $300 \mu \mathrm{L}$ sterile destilled water, and $3 \mu \mathrm{L}$ were spotted on minimal medium plates with $120 \mathrm{mM} 3$ AT.

In another approach, $\mathrm{His}^{+}$colonies, following electroporation, were suspended in sterile water using a spreader. Cell density was determined in a spectrophotometer (Hitachi Instruments, San Jose, CA, USA), and cells were plated at $10^{3}$ or $10^{4}$ per standard $8.5-\mathrm{cm}$ petri dish on the minimal medium with $120 \mathrm{mM} 3$ AT. Colonies grow ing under these conditions appeared after 3-4 days of incubation at $28^{\circ} \mathrm{C}$.

\section{Recombinant DNA Methods}

DNA manipulations were done by standard techniques (13). For Southern blot analysis (15), genomic DNA from yeast cells was prepared as described by Rothstein et al. (12). A synthetic PCR fragment corresponding with part of the open reading frame of the actin gene from $P$. pastoris was used as the control in Southern blot experiments (7).

\section{Shake-Flask Dextranase Expression Studies}

The cultures were grown in $50 \mathrm{~mL}$ yeast peptone (YP) medium with $2 \%$ (v/v) glycerol for $12 \mathrm{~h}$ at $30^{\circ} \mathrm{C}$ and 250 $\mathrm{rpm}$. The cells were then centrifuged at $1500 \times g$, washed twice with the YP medium and resuspended in $50 \mathrm{~mL}$ of the same medium, with $1 \%$ (v/v) methanol instead of glycerol, to induce the $A O X 1$ promoter and dextranase expression. After $24 \mathrm{~h}$ of growth in this medium, additional $0.5 \%(\mathrm{v} / \mathrm{v})$ methanol pulses were given every $12 \mathrm{~h}$ for a total of $72 \mathrm{~h}$.

At this time, the final dextranase activity in the cultures' supernatant was measured according to Kosaric et al. (8). The amount of reducing sugar formed was determined colorimetrically by the dinitrosalicylic acid reagent method (9). One enzyme unit was de- fined as the amount of enzyme that releases $1 \mu \mathrm{mol}$ glucose equivalent in 1 min from dextran T-2000 (Amersham Pharmacia Biotech, Uppsala, Sweden) at $40^{\circ} \mathrm{C}$ and $\mathrm{pH} 5.5$.

\section{RESULTS AND DISCUSSION}

\section{HIS3 Gene Copy Number and 3 AT Resistance}

Our initial goal was to determine whether there was a relationship between a high copy number of the integrated vector that included the HIS3 gene of $S$. cerevisiae and the level of resistance to increasing concentrations of 3 AT. After the transformation of P. pastoris with the pPDEX plasmid (Figure 1A) by the spheroplast method and dot blot analysis of 15 randomly selected transformants probed with the dex gene, we isolated three strains that carried several copies of the inserted vector. Figure $1 \mathrm{~A}$ also illustrates some of the integration events by which the dextranase expression cassette can be inserted into the AOXI locus. Moreover, a detailed analysis of the integration events in P. pastoris was done elsewhere (2).

Chromosomal DNA digested with EcoRI and hybridized to a dex probe showed that, as was expected in a single-copy transformant (strain MPDEX), only a single band of $3.7 \mathrm{~kb}$ was observed (Figure 1B, lane 2). This analysis also shows that for the three multicopy clones, several bands of the expression cassette were inserted into the genome (Figure 1B, lanes 4, 5 and $6)$. When this filter was rehybridized with a $1-\mathrm{kb}$ fragment corresponding to the promoter of the $A O X 1$ gene $\left(P_{A O X I}\right)$, all the fragments, except the $1.8-\mathrm{kb}$ band (Figure 1B, lane 6) that was recognized by the dex gene, were hybridized with the $P_{A O X I}$ probe, indicating that this pattern corresponds to multiple insertions of the expression cassette into the genome (data not shown).

Quantitative DNA dot blots definitively demostrate the multicopy nature of the dextranase gene in the transformants and, in particular, one of these clones (Figure 1B, lane 4) had over 10 copies of the vector inserted in its genome. This strain was denominated MPC3. MPC3 was tested for growth on 
the minimal medium containing increasing concentrations of $3 \mathrm{AT}$ $(0.5-120 \mathrm{mM})$. As a control, we used the single-copy transformant MPDEX, obtained by Roca et al. (10). After three days, both transformants grew well in up to $80 \mathrm{mM} 3 \mathrm{AT}$. However, only MPC3 cells were able to grow in higher drug concentrations (90, 100 and 120 $\mathrm{mM})$. The result of this assay suggests a relationship between the level of resistance to high concentrations of 3 AT and the HIS3 gene copy numbers present in the P. pastoris genome. However, even though there is a direct relationship between resistance and copy number, the 3 AT resistance is not necessarily titratable.

\section{Selection of Multicopy \\ Transformants Using 3 AT}

The selection of multicopy transformants using G418 has been reported in cells transformed by spheroplast or electroporation methods (14). To test the possibility of isolating multicopy transformants using 3 AT, we transformed the MP36 strain by spheroplasting and electroporating with the pPDEX plasmid (10) previously digested with the $P v u I I$ restriction enzyme. This digestion directs integration to proceed by a double homologous recombination mechanism.

After primary selection for $\mathrm{His}^{+}$ transformants, about 30 colonies from each transformation method were spotted on the minimal medium plates containing $120 \mathrm{mM} 3$ AT. While several colonies were obtained from both transformation methods, the number of $3 \mathrm{AT}$ resistant colonies from spheroplast was higher (Figure 2, panels A and B).

We used Southern blot hybridization with the dex gene as a probe to determine the integration pattern of 14 colonies obtained by the spheroplast method. This experiment showed that $80 \%$ of the transformants had more than two bands corresponding to the dex gene inserted into the genome (Figure 3). Southern blot analysis from three colonies obtained by electroporation showed a similar integration pattern (data not shown). These results indicate that both transformation methods will allow the selection of high copy number transformants.
To improve the screening procedure, the MP36 strain was electroporated with the pPDEX plasmid previously digested with $P v u \mathrm{II}$, and the cells were plated on minimal medium agar plates for $\mathrm{His}^{+}$selection and in parallel on the minimal medium with $120 \mathrm{mM} 3$ AT after an overnight incubation at $28^{\circ} \mathrm{C}$. After seven days of incubation, no growth was detected in 3 AT plates, indicating that this method probably does not work for primary selection.

However, in a secondary screening, $789 \mathrm{His}^{+}$transformants were pooled af- ter initial selection on minimal medium plates and spread at a density of $10^{3}$ and $10^{4}$ cells per plate with $120 \mathrm{mM} 3$ AT. In this experiment, the number of colonies that were able to grow in the selection medium was 22 and 240, respectively.

Chromosomal DNA was isolated from 12 transformants and analyzed by Southern blot after digestion with the EcoRI restriction enzyme. In contrast with the Southern analysis from transformants obtained by spheroplasting, in this case, eight transformants showed a single band of about $2.8 \mathrm{~kb}$, and four



Figure 1. Schematic representation of integration events in $\boldsymbol{P}$. pastoris. (A) Map of the expression vector pPDEX, predicted structures and molecular events for single-copy integration and multicopy integration of the dextranase expression vector. Panel 1, single-copy integration by double crossover transplacement, panel 2, single-copy integration by circularization and single crossover insertion; and panel 3, multicopy integration arising by circularization of the dextranase expression cassette followed by single crossover insertion, in addition to the gene replacement event. Black boxes indicate the probe using in the hybridization experiment. (B) Southern blot analysis of different P. pastoris strains. Lane 1, pPDEX plasmid; lane 2, DNA from the MPDEX strain; and lane 3, DNA from the MP36 strain, used as the negative control. Lanes 4-6, DNA from three MP36 transformants that carry several copies of the dex gene (lane 4, strain MPC3; lane 5, strain MPC5; and lane 6, strain MPC9). Lane 7, molecular weight marker ( $\lambda /$ HindIII-P $\left.{ }^{32}\right)$. All DNA was digested with EcoRI and hybridized with the dex gene. 


\section{Research Report}

A.)

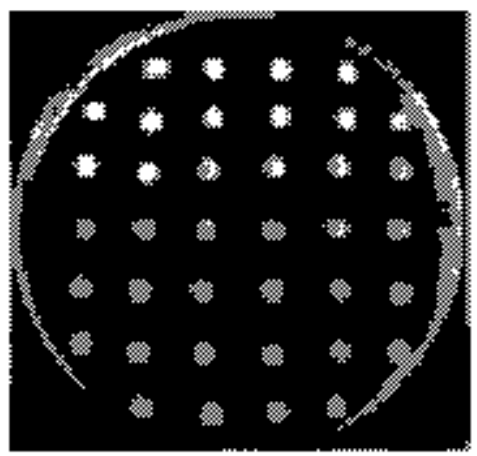

Bi)

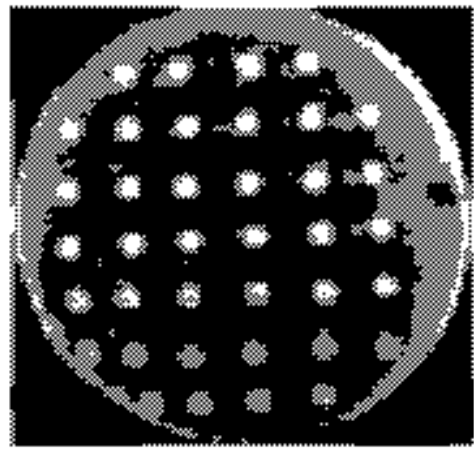

$+3 \mathbf{T}$
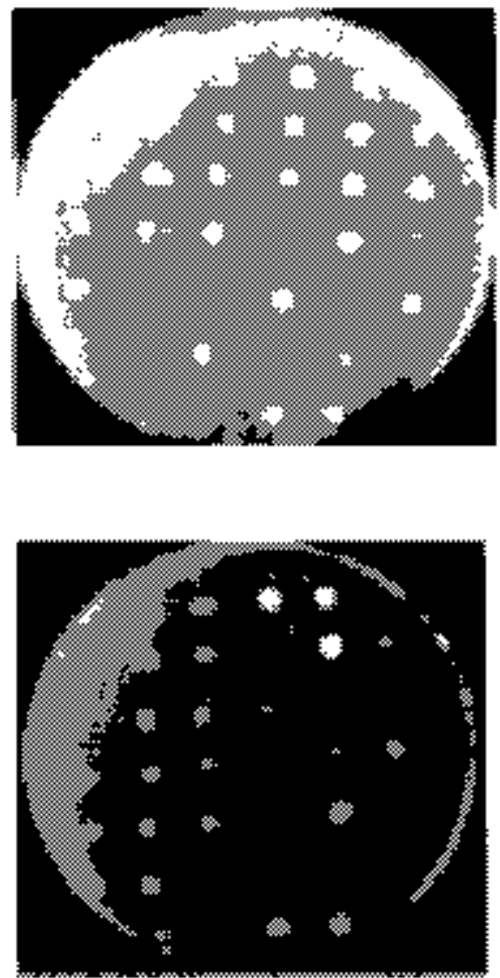

Figure 2. Growth of 30 transformants (MP36, PvuII-cut pPDEX) on minimal medium plates without (left) or with (right) $120 \mathrm{mM} 3$ AT. (A) Transformants obtained by the spheroplast method. (B) Transformants obtained after electroporation. In each plate, the first and last rows are controls (the first two colonies correspond to the multicopy MPC3 strain and the last two to the single-copy MPDEX).

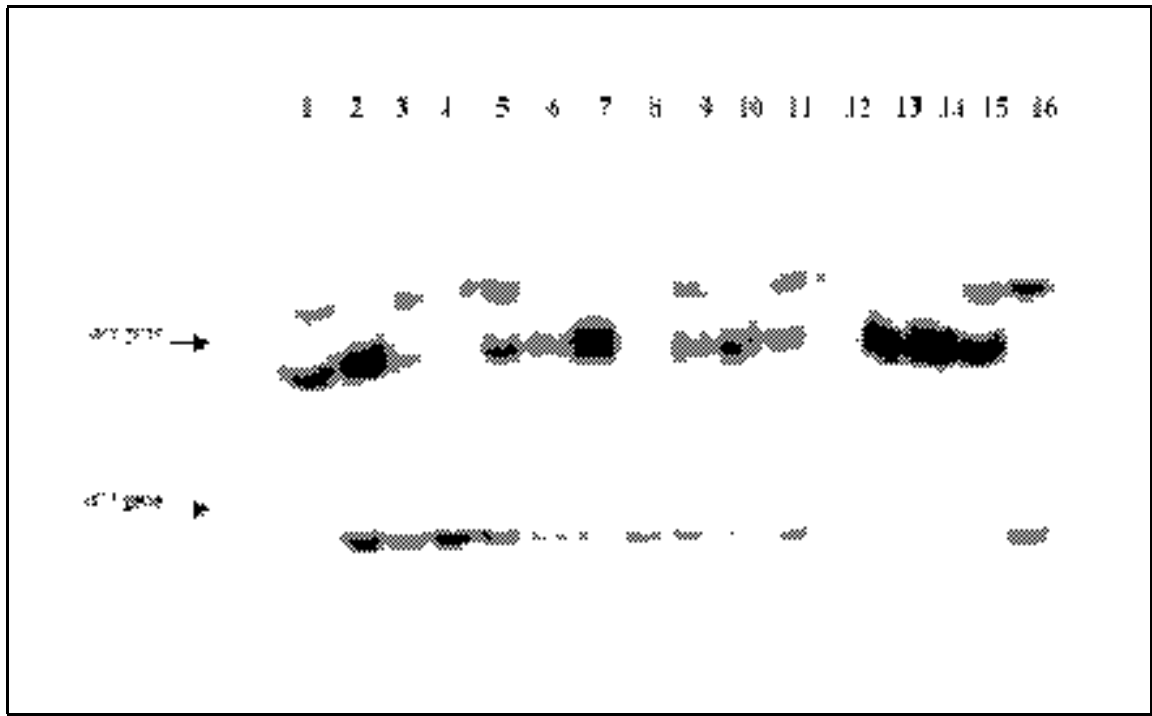

Figure 3. Southern blot analysis of 14 transformants obtained by the spheroplast method, grown in minimal medium plates plus $120 \mathrm{mM} 3 \mathrm{AT}$. The filter was hybridized with the dex gene from P. minioluteum (upper band) and rehybridized with the $A C T$ gene from P. pastoris (lower band) to normalize the amounts of DNA loaded on the gel. Lanes 1-7 and 9-15, DNA from MP36 transformants; lane 8 , DNA from the MP36 strain; and lane 16, DNA from the MPDEX strain. In all cases, the DNA was digested with EcoRI. 
transformants had an additional band of $3.7 \mathrm{~kb}$. However, the difference in the signal obtained between the transformants is clear (data not shown).

As the dextranase-encoding gene has an internal EcoRI restriction site (Figure 1A), this pattern (for the eight transformants with the single $2.8-\mathrm{kb}$ band) is consistent with multiple integrations by single recombinations in the $5^{\prime}$ region of the $A O X 1$ gene. For the other four clones, the pattern is consistent with multicopy integration in the $5^{\prime}$ region of the $A O X 1$ gene in addition to the gene replacement event.

\section{Dextranase Expression in Multicopy Transformants}

The expression of dextranase in the methylotrophic yeast $P$. pastoris was first reported by Roca et al. (10). We recently found that the expression of this enzyme was more efficient in a singlecopy transformant of the his 3 negative strain MP36 than in a single-copy transformant of the his4 negative strain GS115 (7). As we described above, by using the 3 AT resistance, we have selected MP36 transformants carrying several copies of the dex gene. Dextranase activity was measured in the supernatant of the culture of one of these colonies and compared with the dextranase level obtained from a singlecopy transformant. The dextranase activity in the supernatant of the singlecopy transformant MPDEX was about $215 \mathrm{U} / \mathrm{mL}$. This value was higher than that previously reported by Roca et al. (10), which measured the expression on the minimal medium. The analysis of the one multicopy transformant (corresponding to DNA in Figure 3, lane 5) showed that, although this clone has about nine copies of the dextranase expression vector (as was determined by quantitative dot blot), it only has a twofold increase in dextranase activity, about $500 \mathrm{U} / \mathrm{mL}$, compared to the level of activity in a single-copy transformant. This result indicates that perhaps factors other than the copy number limited the dextranase expression in $P$. pastoris.

Although the antibiotic G418 is widely used for the selection of multicopy transformants in $P$. pastoris, this method has certain limitations, such as the false positive colonies that appear even when the cells are plated at low cell density, the high cost of the G418 and the use of an antibiotic resistance gene from bacteria, which limits the use of this selection method in the expression of certain recombinant proteins.

The method described in this study is based on the negative effect of the 3 AT on the activity of the HIS3 gene product. This allows the same gene to be used as an auxotrophic marker and for the selection of multicopy transformants. In addition, the low cost of this compound would make this method an attractive alternative for the selection of multicopy transformants from the his 3 auxotrophic mutant strain of $P$. pastoris.

\section{ACKNOWLEDGMENTS}

We would like to thank Drs. Juana María Gancedo, Carlos Gancedo, Jose A.Cremata and Ms. Mirian Rivas for critical reading and helpful suggestions regarding our manuscript. This work was supported by the research project no. 3082-327 from Centro de Ingeniería Genética y Biotecnología (CIGB).

\section{REFERENCES}

1.Becker, D.M. and L. Guarente. 1991. Highefficiency transformation of yeast by electroporation. Methods Enzymol. 194:182-187.

2.Clare, J.J., F.B. Rayment, S.P. Ballantine, K. Sreekrishna and M.A. Romanos. 1991. High-level expression of tetanus toxin fragment $\mathrm{C}$ in Pichia pastoris strains containing multiple tandem integrations of the gene. BioTechnology 9:455-460.

3. Cregg, J.M., K. Barringer, A.Y. Hessler and K.R. Madden. 1985. Pichia as a host system for transformations. Mol. Cell. Biol. 5:33763385.

4.Cregg, J.M., T.S. Vedvick and W.C. Raschke. 1993. Recent advances in the expression of foreign genes in Pichia pastoris. BioTechnology 1 1:905-909.

5.Fairlie, W.D., P.K. Russell, H.P. Zhang and S.N. Breit. 1999. Screening procedure for Pichia pastoris clones containing multiple copy gene inserts. BioTechniques 26:10421043.

6.Galzy, P. and P.P. Slonimski. 1975. Variation de la levure aucours de la croissance sur l'acide lactique ou sur glucose comme source de carbone. CR Acad. Sci. Paris 245:24232427

7.García, B.M., E. Rodríguez, T. Rivero, Y. Hidalgo and J.J. Menéndez. 2000. Dextranase expression in two different host-vector systems of the methylotrophic yeast Pichia pastoris. Biotechnol. Appl. 17:11-15.
8.Kosaric, N., K. Yu and J.E. Zajic. 1973. Dextranase production from Penicillium funiculosum Biotechnol. Bioeng. 15:729-741.

9.Miller, G.L. 1959. Use of dinitrosalicylic acid reagent for the determination of reducing sugars. Anal. Chem. 31:426-428.

10.Roca, H., B. García, E. Rodríguez, D. Mateu, L. Coroas, J. Cremata, R. García, T. Pons and J. Delgado. 1996. Cloning of the Penicillium minioluteumgene encoding dextranase and its expression in Pichia pastoris. Yeast 12:1187-1200.

11.Romanos, M.A., C.A. Scorer and J.J. Clare. 1992. Foreign gene expression in yeast: a review. Yeast 8:423-488.

12. Rothstein, R. 1985. Cloning in yeast, p. 45 46. In D.M. Glover (Ed.), DNA Cloning II. IRL Press, Oxford

13.Sambrook, J., E.F. Fritsch and T. Maniatis. 1989. Molecular Cloning: A Laboratory Manual. CSH Laboratory Press, Cold Spring Harbor, NY.

14.Scorer, C.A., J.J. Clare, W.R. McCombie, M.A. Romanos and K. Sreekrishna. 1994. Rapid selection using G418 of high copy number transformants of Pichia pastoris for high-level foreign gene expression. BioTechnology 12:181-184.

15.Southern, E.M. 1975. Detection of specific sequences among DNA fragments separated by gel electrophoresis. J. Mol. Biol. 98:503512.

16.Sreekrishna, K., L. Nelles, R. Potenz, J. Cruze, P. Mazzaferro, W. Fish, F. Motohiro, K. Holden et al. 1989. High-level expression, purification and characterization of recombinant human tumour necrosis factor synthesized in the methylotrophic yeast Pichia pastoris. Biochemistry 28:4117-4125.

17.Yong, V., M.E. González, L. Herrera and J. Delgado. 1992. El gen HIS3 de Saccharomyces cerevisiae complementa una mutación his ${ }^{-}$de Pichia pastoris. Biotechnol. Appl. 9:55-61.

Received 3 February 2000; accepted 12 July 2000 .

Address correspondence to:

Dr. Javier Menéndez

División de Bioindustria

Centro de Ingeniería Genética y

Biotecnología

Ave. 31 el 158 y 190

Aptdo 6162

C.P. 10600, La Habana, Cuba

e-mail: javier.menendez@cigb.edu.cu orpf2000_99@yahoo.com 